Revista de Derecho

Universidad Católica del Norte

Sección: Ensayos

Ańo 17 - No 2, 2010

pp. $205-238$

\title{
LA PROBLEMÁTICA DE LAS PARTES Y EL CONTENIDO DE LA LEGITIMACIÓN ACTIVA EN LA CUESTIÓN DE INAPLICABILIDAD POR INCONSTITUCIONALIDAD DE LA LEY ${ }^{*}$
}

\author{
RodRIgo PICA Flores ${ }^{* *}$
}

RESUMEN: El presente trabajo aborda la justificación y el contenido de la legitimación activa en el proceso de inaplicabilidad por inconstitucionalidad de la ley en Chile, en una perspectiva de contexto de un sistema concentrado y concreto, para llegar posteriormente a la diferenciación entre la iniciativa de parte y la que corresponde a juez que conoce del proceso a quo. Se busca justificar la legitimación del juez de la causa, alternativa con la de las partes, pasando por la identificación y contenido de la legitimación pasiva en dicho control de constitucionalidad.

PALABRAS CLAVE: Control jurídico de la Ley - acción de inaplicabilidad - Derecho procesal constitucional - legitimación activa - legitimación pasiva - supremacía constitucional - doble sumisión del órgano judicial.

\section{THE SITUATION OF THE PARTIES AND THE CONTENT OF THE STANDING TO SUE IN THE ISSUE OF INAPPLICABILITY DUE TO UNCONSTITUTIONALITY OF THE LAW}

ABSTRACT: This work deals with the justification and the content of the standing to sue in the process of inapplicability due to unconstitutionality of the law in Chile, with a perspective of the context of a concentrated and concrete system, to later differentiate between the initiative of the party and that belonging to the judge that knows the process a quo. The work also looks to justify the legitimation of the

El presente trabajo ha sido elaborado en el marco del proyecto de investigación FONDECYT regular No 1090607 titulado "Sujetos, objeto y decisión en la cuestión de inaplicabilidad: formulación del marco de principios procesales constitucionales que encuadran el control concreto de constitucionalidad de la legislación y la jurisprudencia", del cual su autor es coinvestigador. Fecha de recepción: 30 de noviembre de 2010.

Fecha de aceptación: 22 de diciembre de 2010.

** Magíster en Derecho, Profesor de Derecho Constitucional en el Programa de Magíster en Derecho Penal de la Universidad Central (Chile) y Profesor de Derecho Político de la Universidad Andrés Bello (CHILE). Correo electrónico: rpicaf@yahoo.es 
judge to the cause, alternative to that of the parties, going through the identification and content of the standing to be sued in said control of constitutionality.

KEY WORDS: Juridical control of the Law - inapplicability action Constitutional procedural Law - Standing of sue - Standing to be sued constitutional supremacy - double submission to the court.

\section{1) Planteamiento Del Problema}

El presente trabajo se circunscribe a una de las cuestiones procesales propias del control de inaplicabilidad por inconstitucionalidad de la ley: la legitimación y su contenido. Sin pretender agotar una temática de tal envergadura, se busca reconocer las razones y los elementos de la legitimación en sentido genérico, para llegar a su contenido e identificar su relevancia en la configuración del sistema de jurisdicción constitucional.

En específico, a partir de dichas nociones, cabe preguntarse cuáles serían las razones que justifican la legitimación activa restringida que establece la Constitución al acotar a las partes -y no habilitar a terceros- la capacidad para requerir de inaplicabilidad por inconstitucionalidad de la ley ante el Tribunal Constitucional, de conformidad al artículo 93, numeral $6^{\circ}$ e inciso undécimo, de la Carta Fundamental.

Por otra parte, se busca una explicación a la introducción de la atribución de los jueces ordinarios para plantear la cuestión de inaplicabilidad, innovación creada por la Ley No 20.050 y la enunciación de las diferencias de esta legitimación activa y la establecida en favor de las partes.

En este sentido se constata que la introducción del control concreto implica que la legitimación activa que, en cuanto a su contenido y titularidad, es distinta con respecto a la que puede conceptualizarse en un sistema de control puramente abstracto. ¿Cómo se determina dicha diferencia y cuál es su significado?

Explicitada la diferencia entre la legitimación en un sistema abstracto y en un sistema de control concreto, se constata que en el sistema chileno debe diferenciarse el rol de las partes y del juez que conoce de la gestión invocada en el proceso de inaplicabilidad, constatándose que no son iguales sus cometidos en la formulación de la cuestión, para finalmente diferenciar, a partir de dichos elementos, el rol del juez ordinario y el rol de las partes en el planteamiento del conflicto de constitucionalidad. 
La problemática de las partes y el contenido de la legitimación activa en la cuestión de inaplicabilidad...

\section{2) INTRODUCCIÓN}

Cabe señalar que "la problemática de las partes en el proceso de inaplicabilidad", forma en que denominaremos la justificación para restringir el acceso al proceso de control concreto de normas, puede abordarse no solo desde una estricta visión procesal, sino también desde una perspectiva procesal constitucional. En este sentido, debe analizarse no solo el concepto teórico de legitimación, sino también, una vez que se llegue al contenido de la misma, es necesario tener presente su relación con principios de carácter estrictamente constitucional, como la dimensión subjetiva de los derechos y la supremacía de la Carta Fundamental, los cuales permitirán dilucidar el significado de la legitimación activa restringida a las partes y al juez de la causa, y las diferencias que existen entre ambas.

Es preciso señalar que no es fácil constatar la convivencia simultánea de las partes y del juez para acceder a la judicatura constitucional concentrada, como ocurre en el sistema chileno. En efecto, en un texto de reciente publicación y partiendo de la base alternativa de dichas opciones de legitimación activa, Groppi clasifica a los sistemas de jurisdicción constitucional según si el acceso al juez de constitucionalidad de la norma es directo o indirecto, partiendo de la base que ambas son opciones excluyentes.

En este sentido, el acceso será directo "cuando el sujeto legitimado puede acudir directamente al juez de la constitucionalidad, sea un juez especializado (un tribunal constitucional), sea un juez ordinario", en términos tales que el "juicio sobre la constitucionalidad de un acto que pueda ser estimado o desestimado por el juez mismo, sin acudir a una instancia

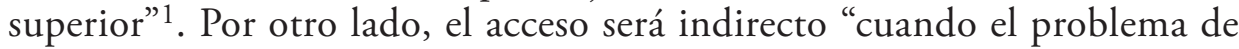
constitucionalidad surge frente a un juez que no puede, por sí mismo, tomar una decisión sobre la inconstitucionalidad que le ha sido presentada, sino que tiene que remitir la cuestión al tribunal especializado"2.

Cabe señalar que, desde esta perspectiva, en Chile la inaplicabilidad obedece a una configuración híbrida: es directo el acceso en la medida que las partes pueden directamente acudir ante el Tribunal Constitucional -no como en los sistemas italiano o espańol, donde el filtro es el juez ordinario- $y$ es indirecto en la medida que la cuestión de constitucionalidad surge en el marco de un juicio de legalidad ordinaria, en el cual el tribu-

\footnotetext{
1 Groppi, Tania (2009). "Titularidad y legitimación ante la jurisdicción constitucional. Una perspectiva comparada”, en Ferrer Mac-Gregor, Eduardo / Zaldívar Lelo de Larrea, Arturo (coordinadores): La ciencia del Derecho procesal constitucional. Estudios en homenaje a Héctor Fix-Zamudio en sus cincuenta años como investigador del Derecho", tomo III, México D.F.: UNAM, pp. 227-255, p. 234.

2 Groppi (2009) 234.
} 
nal a quo no puede declarar por sí la inconstitucionalidad de la norma sin que lo haga el Tribunal Constitucional.

\section{3) CONCEPTO DE LEGITIMACIÓN Y SU CONEXIÓN CON EL INTERÉS DE LAS PARTES}

En primer término, la idea de legitimación alude a la capacidad, a la titularidad de la acción y al ejercicio del derecho de acceso a la jurisdicción. En segundo término, la legitimación siempre se ha clasificado en las perspectivas activa y pasiva, identificando al demandante con el demandado, lo que tiende a confundir la legitimación con las partes.

En realidad, la idea de legitimación pareciera identificarse, por un lado, con el derecho a comparecer y, por el otro, con la titularidad del interés reclamado en el proceso, lo cual conduce hacia la identificación de la parte y la capacidad para obrar.

Las anteriores notas connotativas permiten una primera aproximación conceptual, en términos que "lo que comúnmente entendemos por legitimación constituye un presupuesto procesal o de validez del proceso y no una cuestión de fondo"3.

Hecha la precisión anterior, se puede señalar que la legitimación, conceptualmente hablando y lato sensu, es "el reconocimiento que el ordenamiento jurídico hace en favor de un sujeto, en cuya virtud le confiere la posibilidad de ejercitar eficazmente su poder de acción, en base a la relación existente entre el sujeto y los derechos e intereses legítimos cuya tutela jurisdiccional pretende" 4 .

Pareciera ser entonces que, en primer término, se está frente a una verdadera ecuación, de forma que: legitimación = sujeto + interés.

Puede señalarse que son partes, lato sensu, los titulares de la legitimación, en tanto son las personas que sostienen las pretensiones en conflicto dentro de un proceso, es decir, parte es sinónimo de litigante y, al mismo tiempo, de interlocutor de una relación jurídico-procesal.

Para la doctrina tradicional, la parte puede definirse como "aquel que en nombre propio o en cuyo nombre se pretende la actuación de una norma legal y aquel respecto del cual se formula esa pretensión"5. Fundamentalmente son: el demandante que es la persona que ejercita la acción en protección de su derecho material y por otro lado el demandado, que es

Salas Canceller, Antonio (2006). "La legitimación", en el mismo (coordinador): Las partes: problemática procesal, Madrid: Consejo General del Poder Judicial, pp. 61-85, p. 66.

$4 \quad$ Silguero, Joaquín (1995). La Tutela Jurisdiccional de los Intereses Colectivos a Través de la Legitimación de los Grupos, Madrid: Editorial Dykinson p. 156

5 Alsina, Hugo (1950). Derecho procesal civil y comercial, Tomo I, Buenos Aires: Ediar, p. 473. 
aquel en contra de quien se dirige esa acción, en tanto sería el sujeto obligado a cumplir lo que la sentencia definitiva resuelva. También se considera partes a los terceros admitidos al juicio.

Respecto de asuntos no contenciosos habrá que entender como "parte" al solicitante y también debe hacerse presente que en materia penal el Código Procesal Penal no contiene el concepto de "partes", sino que habla indistintamente de "intervinientes" y "sujetos procesales".

Es posible afirmar que la noción de parte aparece ligada indisolublemente a la de pretensión, y esta obedece necesariamente al ejercicio de una acción.

A partir de ahí se debe necesariamente arribar a la legitimación, que puede ser activa o pasiva según quién sea el demandante y el demandado y que siempre surgirá, en materia de inaplicabilidad, de algún derecho o algún interés de fuente constitucional, lo que, en la praxis, hace que el motivo en este proceso constitucional de inaplicabilidad sea siempre un derecho fundamental.

\section{1) ¿QUÉ SE ENTENDERÁ POR LEGITIMACIÓN ACTIVA?}

Puede señalarse que la primera noción de legitimación activa es lo que usualmente podría llamarse "legitimación ordinaria", entendiendo por tal la que "corresponde al titular de la relación jurídica u objeto litigioso" ", a la que se debe agregar -en un sentido dialéctico- lo que denominaremos "legitimación extraordinaria", conferida de manera expresa por el ordenamiento jurídico-procesal, sin conexión con la titularidad de los intereses en conflicto, pues los mismos son considerados como relevantes y dignos de protección por el sistema jurídico sin considerar su disponibilidad, asunto que, en algunos casos, puede encontrar su fundamento en valores jurídicos de orden o interés público ${ }^{7}$, que se consideran independientemente de la dimensión subjetiva que puedan tener.

Por otra parte, la legitimación pasiva puede ser entendida como un atributo jurídico, "que permite al demandado acudir a un órgano jurisdiccional a defender, mediante el ejercicio de excepciones, una posición jurídica contraria a las pretensiones que la actora hubiere planteado en su contra a través de la demanda, la cual le permite la realización de determinado tipo de facultades dentro de un proceso" 8 .

Por otra parte, un concepto útil y práctico de legitimación activa puede encontrarse en el Derecho procesal constitucional de México, que

Salas CANCEller (2006) 70.

Montero Aroca, Juan (1994). La legitimación en el proceso Civil, Madrid: Editorial Civitas, pp. 49 y ss.

8 Cossio DíAz, José Ramón (2007). "Las partes en las controversias constitucionales", Cuestiones Constitucionales, No 16, enero-junio, pp. 89-135, p. 92. 
ha entendido como "la potestad conferida (al actor) por el orden jurídico para acudir a un órgano jurisdiccional a solicitar, mediante el ejercicio de una acción, la tramitación de un proceso"'.

En tanto capacidad para comparecer, es necesario recoger la división entre la denominada legitimación activa ad processum y la llamada legitimación activa ad causam.

La legitimación ad processum se identifica con el concepto de "capacidad procesal", en términos genéricos, en tanto capacidad general para ocurrir ante un tribunal. La legitimación ad causam encierra mayores complejidades, y se refiere a "la especial naturaleza que emerge de la relación jurídica, determinando el tipo o grado de interés que cada postulante tiene en la órbita de los derechos sustanciales (interés para obrar)" ${ }^{10}$, lo que obliga a analizar las especificidades y peculiaridades de la acción que se ejerce y de la relación jurídico procesal de que se trate.

Es decir, la legitimación ad causam exige un interés actual y comprometido en el conflicto jurídico, sin el cual no podrá hablarse de una "parte" en sentido estricto, al no haber titularidad del interés que se invoca. En términos procesales, la misma se traduce en el objeto de una acción y de una pretensión: la titularidad y el ejercicio de un derecho subjetivo o de un interés cuyo reconocimiento y amparo se solicita declarar al tribunal.

Para comprender el concepto de legitimación ad causam, o fundada en un interés, es necesario diferenciar ambos institutos, por lo que debe tenerse presente que "los conceptos de legitimación e interés, aun cuando están en estrecha relación, deben ser separados para facilitar su comprensión. Si mediante el primero se entiende la posición procesal que corresponde a determinado "sujeto", mediante el segundo se identifica el criterio que debe ser satisfecho a efecto de que ese sujeto esté en posibilidad de participar en un determinado proceso. Mientras que con el concepto de legitimación suele identificarse al "quién", mediante el de interés se identifica al "qué" del proceso"11.

En realidad la legitimación ad causam puede ser identificada como una consecuencia del interés si es que este es reconocido por el sistema jurídico, ya que estará amparado por el Derecho solo si se le reconoce el carácter de justiciable. En el caso que nos convoca, el interés amparado es un derecho fundamental, cuestión que ahorra el estudio de su contenido y, al mismo tiempo, escapa al objeto del presente estudio al ser propio de la teoría general de los derechos fundamentales y no del Derecho procesal constitucional.

\footnotetext{
9 Cossio Díaz (2007) 92.

10 Gozaini, Osvaldo (1996). "Legitimación y proceso", en Augusto M. Morello (coord.): La Legitimación, Buenos Aires: Abeledo Perrot, pp. 39-63, p. 53.

11 Cossio Díaz (2007) 94.
} 
La problemática de las partes y el contenido de la legitimación activa en la cuestión de inaplicabilidad...

\section{2) ¿A QUIÉN CORRESPONDE LA LEGITIMACIÓN ACTIVA EN PROCESOS DE CONTROL DE NORMAS? UNA CUESTIÓN DE CONFIGURACIÓN DEL SISTEMA}

En materia de procesos constitucionales, la legitimación activa puede ser entendida como "la capacidad de activar, o poner en marcha, un proceso constitucional concreto" 12 , cuestión que puede plantearse como "un derecho a acceder a la jurisdicción constitucional que otorga la posibilidad de iniciar un proceso"13. Esta noción tiene como eje la identificación de la legitimación con la titularidad del derecho a la acción constitucional, entendida como manifestación de la tutela judicial efectiva demandada por una parte, en tanto derecho fundamental, conceptualizado como "aquel que tiene toda persona a obtener tutela efectiva de sus derechos e intereses legítimos ante el juez ordinario predeterminado por la ley y a través de un proceso con todas las garantías, sin dilaciones indebidas y en el que no se produzca indefensión" ${ }^{14}$; que incluye el libre acceso a la jurisdicción, la obtención de una resolución acerca de la pretensión deducida, la ejecución de las resoluciones judiciales, la interdicción de la indefensión, y el derecho al debido proceso, con todos los elementos del mismo.

De esta forma, la legitimación activa es nada menos que la llave de acceso a la apertura del proceso como medio de tutela de derechos y como forma de resolución de conflictos. Consecuencialmente, es también la vía de acceso al sistema de jurisdicción constitucional. A través de su estudio se determina quién y cuándo puede plantear una pretensión y obtener una sentencia fundada en Derecho a partir de la norma constitucional.

Aun cuando desde un prisma puramente procesal parezca desconectada de la problemática de la legitimación, resulta de gran relevancia aquella clasificación de sistemas de control que distingue entre los que están centrados en el control abstracto y aquellos centrados en el control concreto, en la medida que "la contraposición que hoy se presenta como de mayor importancia no es más entre sistema americano y sistema europeo, sino entre sistemas concretos y abstractos de control de constitucionalidad de las leyes" 15 , temática dentro de la cual en el sistema chileno conviven ambos tipos de control.

12 Torres Muro, Ignacio (2008). "Problemas de legitimación en los procesos constitucionales", Revista de Derecho Político UNED, No 71-72, pp. 609-640, p. 610.

13 Canosa Usera, Raúl (1992). La legitimación autonómica en el proceso constitucional, Madrid: Ed. Trivium, p. 66.

14 Balaguer Callejón, Francisco et alii (2005). Derecho Constitucional, tomo II, Madrid: Tecnos, p. 215.

15 Pizzorusso, Alessandro (2007). Justicia, Constitución y Pluralismo, Lima: Palestra, p. 125. 
Partiendo de la base aceptada del carácter concreto del control de inaplicabilidad $^{16}$, cabe reconocer que este tipo de temática tendrá o no relevancia a partir de la configuración del sistema de jurisdicción constitucional del cual se trate, ya que, por ejemplo, si se estructura a partir del control incidental, concreto y difuso, propio de la judicial review norteamericana, el tema de la legitimación de las partes del proceso constitucional de control de normas se reducirá a determinar quiénes son las partes del proceso y a partir de ello cuáles son las partes habilitadas para formular la cuestión, lo que se puede responder a partir de los caracteres básicos de la revisión judicial a partir de 1803, en función de lo cual se exige: "que exista una parte procesal, a la cual la norma legal le produzca un agravio suficiente y actual, que por la vía jurisdiccional ordinaria pueda obtener reparación en defensa de sus derechos (...) debe existir un hecho específico concreto que demuestre la existencia de un daño o agravio (injury) directo e inmediato que sufre la persona del demandante, producido por el demandado (relación de causalidad: causation), que puede ser superado o remediado (redress) por una decisión favorable del tribunal"17, es decir, se requiere:

(a) Existencia de un proceso

(b) Ser parte del mismo

(c) Daño a bienes jurídico-constitucionales

(d) Posibilidad de enmienda de dicho daño a partir de una resolución fundada en la Constitución.

Así, en el sistema norteamericano, origen y caracterización primaria del sistema concreto, la legitimación activa le corresponderá, por regla general, a quien al mismo tiempo es parte del proceso y titular de los intereses constitucionales en cuestión dentro del mismo, es decir, solo a las partes del juicio y no al tribunal; cuestión que puede perfectamente extrapolarse a nuestro sistema y remitirlo a las partes de la gestión judicial en la cual incide el requerimiento de inaplicabilidad, tal como aparece reconocido hoy en el artículo 93 de la Constitución.

16 Ver, por ejemplo, Ríos Álvarez, Lautaro (2005). "Trascendencia de la reforma constitucional en la fisonomía y las atribuciones del Tribunal Constitucional". Estudios Constitucionales, Año 3, N. 1, Ediciones Universidad de Talca; Gómez Bernales, Gastón (2005). "La reforma constitucional a la jurisdicción constitucional”, en Zúńiga Urbina, Francisco (coordinador). Reforma constitucional, Santiago: LexisNexis; ZúŃiga Urbina, Francisco / Vega Méndez, Francisco (2006). "El nuevo recurso de inaplicabilidad por inconstitucionalidad ante el Tribunal Constitucional. teoría y práctica". Estudios Constitucionales, Año 4, No 2; Fermandois V., Arturo (2008). "Inaplicabilidad y control concreto del Tribunal Constitucional: enjuiciando la arbitrariedad en la aplicación de la ley”. Actualidad Jurídica, $\mathrm{N}^{\circ} 17$.

17 Nogueira Alcalá, Humberto (2003). "Tópicos sobre jurisdicción constitucional y tribunales constitucionales", Revista de Derecho de la Universidad Austral de Chile, Vol.14. pp. 43

- 66. Disponible en http://mingaonline.uach.cl/scielo.php?script=sci_arttext\&pid=S071809 502003000100003\&lng=es\&nrm=iso [Fecha de visita: 3 de noviembre de 2010]. 
Sin embargo, puede observarse que a partir de dichos presupuestos de la judicial review, la titularidad de la acción de control constitucional pareciera ser de las partes del proceso ordinario y el rol del juez solo se circunscribe a recibir la solicitud y resolverla según el mérito del caso, la norma impugnada y la preceptiva constitucional.

Por otro lado, en un sistema concentrado, que reconozca como eje el control principal y abstracto, el interés presente en la declaración de inconstitucionalidad será el carácter general y abstracto de la ley, la vigencia erga omnes de la supremacía de la Constitución y a partir de ello la legitimación se traducirá en una acción pública o en un requerimiento de un órgano dotado de legitimidad democrática directa y de una legitimación extraordinaria reconocida por el sistema jurídico a través de una norma expresa, cuestión que en nuestro sistema aparece a propósito del control de constitucionalidad de decretos supremos, por ejemplo.

Por otro lado, debe tenerse presente que con posterioridad a la Segunda Guerra Mundial la evolución de la justicia constitucional admite otra categorización, de carácter más bien funcional, que permite distinguir entre los sistemas de jurisdicción constitucional centrados en el control de normas -que reconocen la cuestión de constitucionalidad como eje- y los sistemas centrados en la protección de derechos, que reconocen al amparo como eje. En este sentido, cabe aludir, en el primer caso, por ejemplo, lo que hoy es el sistema francés de control de normas, o más puramente los casos italiano y portugués, que disponen de Tribunales Constitucionales, pero sin amparo extraordinario. Por otro lado, a pesar de reconocerse la existencia e importancia del proceso de inconstitucionalidad, el sistema mexicano nace y se desarrolla centrado en el amparo.

En este sentido, es menester reiterar que, funcionalmente, el control abstracto de normas, en principio obedece a intereses generales, la supremacía de la Constitución como norma superior, como piedra roseta del sistema de fuentes, entendida como la norma que establece los elementos de orden público del sistema jurídico y el reparto de potestades, cuya fuerza jurídica constituye un valor de carácter objetivo y de vigencia erga omnes, en tanto norma de carácter general y abstracto. Es por ello que este tipo de controles suelen tener eficacia general y además, como ya se dijo, se inician por vía de acción pública o bien por medio de un requerimiento de algún órgano político o minoría parlamentaria.

Así, en sistemas centrados en el control de normas y de carácter abstracto la legitimación de las acciones constitucionales no es una cuestión de difícil tratamiento y puede resumirse -aunque por cierto no agotarseen los planteamientos antes expuestos.

En cambio, las cuestiones de constitucionalidad de carácter concreto, que pueden construirse a partir del control de normas -el caso de la inaplicabilidad- o directamente en sede de amparo, aparecen fundadas en la invocación de derechos subjetivos o del interés legítimo de una per- 
sona, ajena al ejercicio de potestades públicas, que es parte en un proceso jurisdiccional cualquiera.

Este tipo de cuestiones caben más bien en la esfera de lo individual, eventualmente dentro de lo disponible y sin duda corresponden a temas propios de bienes jurídicos de titularidad de la persona, no obstante ser -al mismo tiempo- Derecho objetivo las normas constitucionales en que se funda. En este sentido, se está en presencia del elemento ad causam de la legitimación ordinaria, que es el sustento de la tutela constitucional que se reclamará.

Es así que es el titular de los intereses individuales en conflicto, legitimado ad causam ordinario, quien debe decidir si ejerce o no las acciones respectivas en caso de conflictos de constitucionalidad de tipo concreto, sin que se pueda prescindir de su condición de interesado y titular de los derechos que serán ventilados en el proceso.

En efecto, en los procesos de control concreto es posible observar un desplazamiento de los intereses en cuestión, pues si en los controles abstractos son generales y de carácter público, en el control concreto el elemento subjetivo del derecho de rango constitucional en cuestión hace emerger una clara connotación de interés individual, en la medida que el proceso puede ser entre particulares o bien entre un particular y un órgano estatal, se referirá generalmente a situaciones jurídicas disponibles y sin eficacia general.

A partir de lo antes seńalado, es posible afirmar que, al menos en sus orígenes, "el modelo centrado en la ley encuentra su aspecto característico en el control abstracto, mientras que el modelo centrado en la defensa de los derechos lo encuentra en el control concreto y en el recurso directo individual: la tendencia de los sistemas concentrados sería la de un desplazamiento del primero al segundo modelo, esto es, hacia una jurisdicción constitucional fundada en la defensa de los derechos"18, cuestión que ha dado pie a que hoy convivan ambas tendencias funcionales en un sistema de jurisdicción constitucional, pero con una de ellas como eje predominante, como ya se viera.

Esta evolución del sistema concentrado hacia los derechos fundamentales como eje del sistema tiene un origen muy temprano, en el año 1929, con la introducción del control incidental de constitucionalidad, en el marco de la actividad jurisdiccional ordinaria, en la Austria del año 1929, lo que significó que, a lo menos indirectamente, el acceso a la justicia constitucional de control de normas se acercó al ciudadano, en la medida que se encontrara en situación de ser parte en un proceso jurisdiccional, cuestión que con posterioridad a la Segunda Guerra Mundial llegará a ser una nota configurativa de algunos sistemas europeos, como los de

18 Groppi (2009) 232. 
Italia y España, en los cuales el control incidental es una de las principales atribuciones del Tribunal Constitucional.

La evolución reseñada constituye parte importante del marco conceptual dentro del Tribunal Constitucional chileno, en cuanto a su organización y atribuciones ha evolucionado desde un eje constituido por un control de carácter concentrado, abstracto y preventivo, prerreforma 2005, hacia otro eje de control ex post y de carácter concreto, fundado en afectación de derechos por acto de aplicación de normas en un proceso ordinario, que es el control de inaplicabilidad.

Resulta relevante destacar que, en los hechos, los procesos de inaplicabilidad se han fundado hasta la fecha, sin excepción, en infracción a derechos fundamentales, en tanto los mismos son siempre las normas constitucionales que se invocan como infringidas en los requerimiento que se interponen, lo que indica que la legitimación activa pareciera estar ligada a la titularidad y el ejercicio de los derechos fundamentales invocados, cuestión que justifica y da coherencia a un sistema basado en la iniciativa de las partes para acudir al Tribunal Constitucional.

\section{3) ¿A QUIÉN CORRESPONDE LA LEGITIMACIÓN PASIVA EN UN PROCE- SO DE CONTROL CONCRETO DE NORMAS CON RANGO DE LEY?}

Partiendo del concepto de legitimación pasiva ya enunciado, cabe tener presente que se detecta la siguiente configuración conceptual:

El control concreto recae en la actividad de aplicación de normas, es decir, una especie de examen de actividad jurisdiccional.

En el marco de un sistema concentrado será el juez ordinario, por tanto, el destinatario y obligado al cumplimiento de la sentencia de control concreto, por lo cual pareciera que él es el legitimado pasivo, pero en realidad no es así, ya que el interesado en la aplicación de la norma impugnada es la contraparte del requirente en la gestión judicial invocada, pues a él beneficia o concierne la aplicación del precepto, al referirse a sus derechos e intereses, lo cual no ocurre respecto del juez. Sin embargo, el interesado en la aplicación de la norma cuya aplicación está cuestionada es la contraparte del requirente, no el juez. Por ello es dicha contraparte del juicio a quo el real legitimado pasivo y por eso es él, y no el juez, el titular del derecho a formular observaciones y solicitar el rechazo del requerimiento de inaplicabilidad. 


\section{4) LA LEGITIMACIÓN EN EL PROCESO DE INAPLICABILIDAD POR IN-} CONSTITUCIONALIDAD DE LA LEY EN CHILE

\section{1) LA NORMATIVA VIGENTE ACERCA DE LAS PARTES Y SU LEGITIMA- CIÓN EN MATERIA DE INAPLICABILIDAD}

En este sentido, el artículo 93 inciso undécimo, de la Constitución dispone que en materia de inaplicabilidad "la cuestión podrá ser planteada por cualquiera de las partes o por el juez que conoce" de la gestión pendiente ante tribunal ordinario o especial. Por otra parte, el artículo 79 de la Ley $\mathrm{N}^{\circ} 17.997$ dispone que "es órgano legitimado el juez que conoce de una gestión pendiente en que deba aplicarse el precepto legal impugnado, y son personas legitimadas las partes en dicha gestión".

En cuanto a las partes de la gestión en que incide la cuestión de inaplicabilidad, debe remitirse a la ley adjetiva correspondiente, ya que al ser la inaplicabilidad un control de tipo concreto, debe acreditarse la existencia de un interés específico en la aplicación de la norma en cuestión, en el marco de le gestión invocada, razón por la cual la Constitución entregó legitimación activa de inaplicabilidad a las partes de la gestión.

También, cabe señalar que sin perjuicio de lo establecido en el artículo 3 de la Ley $\mathrm{N}^{\circ} 17.997$, en orden a que "El Tribunal solo podrá ejercer su jurisdicción a requerimiento de las personas y los órganos constitucionales legitimados de conformidad con el artículo 93 de la Constitución Política de la República o de oficio, en los casos señalados en la Constitución Política de la República y en esta ley”, el concepto de partes en estos procesos constitucionales no se encuentra definido en la normativa especial.

Del mismo modo, cabe indicar que, a pesar de las anteriores enunciaciones conceptuales y sin hacer mayores definiciones, el artículo 79 de la Ley Orgánica del Tribunal Constitucional, hacen sinónimo a la parte demandante de inaplicabilidad con el "legitimado" para interponer la acción, al establecer como tales al juez y a las partes, en una terminología distinta de la establecida en la Constitución, que no utiliza el concepto de "legitimación", sino que solo alude a la "capacidad" para plantear la cuestión, en acto que, entendido a partir de la buena fe del legislativo, busca lograr una aparente conexión de la legitimación a la calidad de parte más que al interés específico.

Cabe recordar que desde 1925, fecha de creación del control de inaplicabilidad, su iniciativa siempre estuvo entregada a las partes del proceso en el cual incidía la acción constitucional. Por lo expuesto, es necesario recordar las nociones generales del Derecho procesal civil, en el cual puede existir una parte, o pluralidad de partes, activas o pasivas, y a ellas se les pueden sumar los que actúan como terceros, coadyuvantes, excluyentes o independientes, que son las llamadas partes tardías. 
En el antiguo Código de Procedimiento Penal, eran partes el o los querellantes y el o los procesados, como igualmente en cuanto a las pretensiones civiles pueden serlo el actor civil y los terceros civilmente responsables.

La situación se complica a raíz de la terminología del Código Procesal Penal, que habla de "sujetos procesales" y de "intervinientes", y por lo tanto deben asimilarse a la exigencia de "ser parte" señalada en la Constitución. Este tema deberá ser resuelto caso a caso por el Tribunal Constitucional, especialmente si el requerimiento es planteado por algún representante del Ministerio Público o decidir si el imputado o solo el formalizado se asimilan a la figura prescrita por la Constitución.

Cabe entonces preguntarse ¿cuál es el contenido que la jurisprudencia del Tribunal Constitucional le ha asignado a la legitimación de parte?

En este sentido, revisada la jurisprudencia del Tribunal Constitucional, de fondo y de inadmisibilidad, es poco el material que se encuentra respecto de este tema, siendo las resoluciones más explícitos aquellas referidas a la inaplicabilidad del denominado "Turno del Abogado" (sentencia Rol No 755, que se citará más adelante) y la del denominado "Caso Pingueral" (Rol No 1215).

Por ejemplo, el denominado "Caso Pingueral", relativo a acceso a playas, se planteó una excepción de falta de legitimación activa, al sostenerse que los requirentes no eran dueńos de ningún predio comprometido en el litigio. Recordando que la sentencia en cuestión es anterior a la Ley No 20.381, el Tribunal Constitucional se atuvo al mérito del certificado emitido por el tribunal de la gestión pendiente, que hacía fe de la calidad de parte, razonando que "El inciso décimo primero del artículo 93 de la Constitución dispone que podrán solicitar la inaplicabilidad de un precepto legal cualquiera de las partes en la gestión pendiente o el juez que conoce del asunto. En la especie, los actores que han requerido a este Tribunal han acreditado, con el documento que rola a fs. 32, ser parte reclamante en la gestión pendiente. Ello es suficiente para tener legitimación activa para requerir la inaplicabilidad del precepto legal y, por tanto, para rechazar la excepción así entendida. La entidad y cuantía del interés comprometido por la actora en la gestión pendiente es una cuestión que debe discutirse en ella. Mientras los requirentes permanezcan como parte en una gestión, no le compete a este Tribunal juzgar la legitimidad de ser parte en ella"19, para señalar posteriormente que "La entidad y cuantía del in-

19 Tribunal Constitucional de Chile, sentencia de 30 de abril de 2009, Rol No 1215, Requerimiento de inaplicabilidad por inconstitucionalidad de "Inversiones Pingueral Ltda.", "Inmobiliaria Pingueral S.A." e "Inmobiliaria e Inversiones Costa Pingueral Ltda.", y don Gustavo Yánquez Mery respecto del artículo 13 del Decreto Ley No 1.939, de 1977, en el juicio sumario sobre reclamo deducido contra resolución administrativa, Rol No C/4193/2008, caratulado "Inversiones Pingueral Ltda. y otros con Fuentes Fuentealba, Ma- 
terés comprometido por la actora en la gestión pendiente es una cuestión que debe discutirse en ella. Mientras los requirentes permanezcan como parte en una gestión, no le compete a este Tribunal juzgar la legitimidad de ser parte en ella".

En la resolución citada no se examina el interés constitucional comprometido que se invoca, tampoco su contenido, sino que se da por hecho que la norma constitucional zanja la cuestión, en la medida que siendo parte en el juicio en que incide el requerimiento se estaría habilitado para requerir; en función de dicha regla, si el tribunal a quo consideró parte al compareciente, tiene la calidad de legitimado activa para plantear la solicitud de inaplicabilidad. Un razonamiento de lógica pura difícil de desvirtuar, pero que admite observaciones: en primer término, desplaza el eje de la legitimación activa -el interés constitucional- a la cuestión de fondo y extrae su examen de la órbita del Tribunal Constitucional, lo cual sí parece discutible, ya que le vedaría el examen del contenido de la legitimación. No obstante, en segundo término es posible afirmar que por esta vía se reconoce que el interés comprometido es un derecho reconocido por la Carta Fundamental.

Esta línea, consistente en constatar la calidad de parte en el proceso a quo sin examinar el contenido del interés constitucional involucrado, no es aislada, pues el mismo razonamiento puede verse también en otras sentencias, en tanto también el Tribunal Constitucional, al examinar si el libelo fue formulado o no por los titulares de la acción. En efecto, a propósito de requerimientos formulados en el marco de procesos de protección, sostuvo que "la inaplicabilidad es formulada precisamente por los recurrentes en la acción de protección, actualmente en apelación, por lo que tiene la calidad de parte en la gestión referida en el considerando anterior" 20 .

Por otro lado, debe reiterarse que, además de concretizar el proceso de inaplicabilidad, la reforma constitucional del año 2005 extendió la legitimación activa al juez que conoce de la causa, en una innovación que parece seguir los moldes del Derecho europeo, por todo lo cual se ha superado el paradigma del control concentrado-abstracto. En este sentido,

ría Angélica”, del Tercer Juzgado de Letras de Concepción, considerando 5º. Disponible en http://www.tribunalconstitucional.cl/index.php/sentencias/view/1130 [Fecha de visita: 15 de octubre de 2010].

20 Tribunal Constitucional de Chile, sentencia de 31 de marzo de 2008, Rol No 755, "Requerimiento de inaplicabilidad presentado por el abogado Sergio Toloza Rodríguez y el Presidente del Colegio de Abogados de Chile A.G., don Sergio Urrejola Monckeberg, en su representación, respecto del artículo 595 del Código Orgánico de Tribunales, en causa Rol No 6626-2006,caratulada "Sergio Toloza Rodríguez con Juez de Familia de Osorno", en la Corte Suprema”. Disponible en http://www.tribunalconstitucional.cl/index.php/sentencias/ view/906 [Fecha de visita 23 de septiembre de 2010]. El mismo razonamiento se sigue en las sentencias roles $\mathrm{N}^{\circ} \mathrm{s} 1140$ y 1448 . 
se constata la convivencia de la legitimación activa por parte del ciudadano con la de iniciativa judicial, lo que a su vez hace necesario abordar el contenido de esta última.

En esta materia, lo primero consiste en recordar que el control concreto de constitucionalidad es control de actividad jurisdiccional y no un control de actividad legislativa directo y puro.

En el caso específico del Tribunal Constitucional de Chile, en materia de inaplicabilidad por inconstitucionalidad, se trasladó la preeminencia del juicio de constitucionalidad, desde la formulación de la ley hacia el escrutinio de los efectos que produce su aplicación, al sustituirse del antiguo artículo 80 la frase "precepto legal contrario a la Constitución" proveniente de la Constitución de 1925, por la fórmula "precepto legal cuya aplicación en cualquier gestión que se siga ante un tribunal ordinario o especial, resulte contraria a la Constitución", contenida en el numeral $6^{\circ}$ del actual artículo 93.

Así, en controles de constitucionalidad de normas de carácter abstracto, el sujeto pasivo de la acción -legitimado pasivo- es el legislador y el objeto de control es el acto normativo denominado ley. En cambio, en sede de control concreto el objeto de control es diferente, ya que se evalúa la conformidad constitucional del acto de aplicación y sus efectos, cuestión que es parte del ejercicio de la actividad jurisdiccional y no de la sola producción legislativa en un sentido aislado.

Cabe recordar, en este sentido, que ya antes de la reforma constitucional del ańo 2005, podía encontrarse doctrina a partir de la cual el objeto de control del proceso de inaplicabilidad puede conceptualizarse desde la actividad jurisdiccional y no desde la actividad normativa, en tanto se seńalaba que "la sentencia que acoge el recurso de inaplicabilidad no afecta la validez, sino la aplicabilidad para el caso del precepto legal en cuestión. La validez de la ley permanece inalterada. Siendo la ley válida, ella es aplicable a todos los casos que son cubiertos por ella, con la excepción de aquel para el cual la ley fue declarada inaplicable por inconstitucionalidad"21.

Tras las reformas introducidas el año 2005, está claro que la pretensión planteada por el requirente consiste en que se "inaplique un precepto legal" por causar resultados contrarios a la Constitución su aplicación a un caso concreto.

21 Atria Lemaitre, Fernando (2001). "Inaplicabilidad y coherencia: contra la ideología del legalismo". Revista de Derecho de la Universidad Austral de Chile, Vol.12, No 1, pp. 119-156, p. 137. 


\section{2) El JUEZ DE LA CAUSA: DE AUTOR DEL ACTO A CONTROLAR Y APA- RENTE LEGITIMADO PASIVO A UN LEGITIMADO ACTIVO RECONO- CIDO POR LA CONSTITUCIÓN}

Para desentrañar el rol del juez ordinario en el proceso de inaplicabilidad no basta la actividad de reconocer potestad mediante la lectura y acatamiento ciego de lo dispuesto por el constituyente y el legislador orgánico, sino que como cuestión previa cabe preguntarse: ¿quién realiza el acto de aplicación de ley que se cuestiona? En función de lo ya señalado en términos generales, la respuesta es una sola: la aplicación de normas la realiza el tribunal del fondo dictando resoluciones y ejecutando actos procesales, todo lo cual produce el resultado que se tacha de inconstitucional, de forma tal que el juez pareciera ser un legitimado pasivo de la acción de inaplicabilidad, o a lo menos el destinatario de la sentencia dictada por el Tribunal Constitucional, en tanto es el sujeto obligado a su acatamiento y ejecución, pues su deber de utilizar la norma de Derecho objetivo a la hora de adjudicar el derecho subjetivo de cada parte del proceso que está llamado a resolver, se verá interferido por la sentencia del Tribunal Constitucional, que lo inhibirá de aplicar la ley y lo obligará a dar ejecución de manera inmediata y directa a la norma fundamental.

En efecto, es el juez ordinario el primer sujeto pasivo de la sentencia de inaplicabilidad, pues es él quien se verá impedido de utilizar el precepto declarado inaplicable; es él quien deberá aplicar la Constitución de manera inmediata y directa en el sentido y alcance que la sentencia de inaplicabilidad establezcan y es él quien debe hacer aplicación del precepto que se interpreta de conformidad a la Constitución en la resolución del conflicto jurídico-constitucional de inaplicabilidad ${ }^{22}$. Además, de acuerdo a la pretensión formulada por el requirente, para acoger o rechazar una acción de inaplicabilidad debe ser evaluado el resultado eventual de la labor jurisdiccional del tribunal que conoce del asunto, lo que debe entenderse por aptitud decisiva de la aplicación del precepto impugnado, en la medida que un ejercicio de control concreto de inaplicabilidad exige el examen de los siguientes puntos:

(a) El juicio de relevancia, en tanto se evalúa la aptitud relevante del objeto controlado -acto de aplicación de precepto legal-, para generar un resultado específico susceptible de escrutinio constitucional. En términos científicos puede definirse como el examen de "la "aplicación directa" que

22 Ver, por ejemplo, Tribunal Constitucional de Chile. Sentencia de 13 de mayo de 2008. Rol No 993-07 "Requerimiento de inaplicabilidad presentado por Paul Morrison Cristi, respecto del artículo $4^{\circ}$ de la Ley $\mathrm{N}^{\circ} 20.000^{\prime}$. Disponible en http://www.tribunalconstitucional.cl/index.php/sentencias/view/934 [Fecha de visita 23 de noviembre de 2009]. 
efectúe cualquier juez de una disposición o norma constitucional en el marco de la actividad de búsqueda de la norma a aplicar al caso del que está conociendo, cuando el juez deduzca de ahí la derogación (o, de cualquier forma, la no aplicabilidad) de una disposición o norma legislativa ordinaria" por pugnar con la Constitución ${ }^{23}$.

(b) Ponderar la doble función del objeto de control, en tanto el proceso a quo y al acto de aplicación a evaluar es el marco factual dentro del cual la decisión de inaplicabilidad ha de tener efecto y, al mismo tiempo, pasa a ser parte misma del parámetro de control, pues para ponderar los efectos de la aplicación en el "juicio de relevancia", el conflicto y los caracteres de hecho y Derecho del juicio a quo deben ser examinados por el órgano de jurisdicción constitucional al resolver la cuestión planteada.

El razonamiento ya enunciado forzosamente conduce a concluir que el examen de control concreto se centra -o debiera centrarse- en el ejercicio de actividad jurisdiccional y en el resultado del uso que el jurisdictor ordinario hace de los preceptos legales, mas no en el mero contraste de la ley con la Constitución. Este enunciado argumentativo no es de común uso en nuestro medio y, salvo las tesis de Aldunate, Román y Núñez ${ }^{24}$ acerca de lo que debiera ser la naturaleza de la inaplicabilidad por inconstitucionalidad, lo usual es que esta se defina como un control de normas y no como un medio de examen de la actividad judicial, lo que en vez de hacer patente el problema que significa enunciar cuál es el rol del juez, lo elude y hace que la capacidad del juez de la causa para plantear la cuestión y requerir al Tribunal Constitucional sea vista solo como una novedad, pero no como un problema conceptual.

Como bien es sabido, el sistema chileno de control de preceptos legales vigentes se inicia con el texto original de la Carta de 1925, que en su artículo 86 establecía:

"La Corte Suprema, en los casos particulares de que conozca o le fueren sometidos en recurso interpuesto en juicio que se siguiere entre otro Tribunal, podrá declarar inaplicable, para ese caso, cualquier precepto legal

23 Pizzorusso, Alessandro (2006). "La justicia constitucional italiana, entre modelo difuso y modelo concreto", en Requejo Pagés, Juan Luis (coordinador): "Fundamentos, cuadernos monográficos de Teoría del Estado, Derecho Público e Historia constitucional, $\mathrm{N}^{\circ} 4$ de la serie: La rebelión de las Leyes: Demos y nomos: la agonía de la justicia constitucional", Oviedo, Junta General del Principado de Asturias, pp. 239-261, p. 251.

24 Núñez Poblete, Manuel Antonio (2008). "El control de la igualdad en la aplicación de la ley como factor de expansión del control concreto de constitucionalidad de las leyes", en Aa. Vv.: Sentencias destacadas 2007, Santiago: Instituto Libertad y Desarrollo.; Aldunate Lizana, Eduardo (2007). "La reforma constitucional del año 2005 desde la teoría del Derecho y la teoría de la Constitución". Revista de Derecho Público No 69, tomo I, pp. 35 - 57 y Román Cordero, Cristián (2010). "El requerimiento de inaplicabilidad por inconstitucionalidad como mecanismo de control de la arbitrariedad del legislador". Revista de Derecho Público No 72 , pp. 342-182. 
contrario a la Constitución. Este recurso podrá deducirse en cualquier estado del juicio, sin que se suspenda su tramitación".

Cabe señalar que la inaplicabilidad originaria nace entonces en el marco de un juicio, "por vía de recurso" y a solicitud de las partes, de lo cual se puede decir que, el sistema chileno de control de normas nace con elementos de:
(a) Incidentalidad
(b) Principio dispositivo
(c) Competencia específica.

Es del caso destacar que el enjuiciamiento de la ley no estaba otorgado a un requerimiento de órgano político ni tenía efectos erga omnes, ni tampoco se realizaba a solicitud del tribunal que tramitaba el juicio en el que se aplicaría la norma.

Queda claro que el planteamiento y discusión de la cuestión de constitucionalidad quedaba entregada a las partes del juicio sin que el juez ordinario tuviera rol alguno en el proceso de inaplicabilidad.

Sin embargo, en casos de control concentrado e incidental, es usual que las partes tengan solo un rol de "promotores" de la cuestión, al plantear la duda de constitucionalidad ante el juez ordinario, quien con audiencia de las partes decidirá si requiere o no al Tribunal Constitucional en lo que se ha denominado "la prejudicialidad" respecto del inicio del proceso ante el Tribunal Constitucional, entendiendo que es dicho juez, y no las partes del proceso, quien está dotado de legitimación activa para poner en movimiento a la Judicatura Constitucional.

Así, por ejemplo, en el sistema italiano la "prejudicialidad" es hoy uno de los aspectos centrales del sistema ${ }^{25}$ de control, pues en dicha etapa el juez ordinario escucha a las partes, se plantea la duda de constitucionalidad, determina si la norma será o no aplicable al caso y finalmente si es o no interpretable y aplicable de conformidad a la Constitución, en lo que se ha denominado un "monopolio de rechazo". En esta misma etapa, el juez ordinario es quien realiza, en el caso italiano, el juicio de relevancia y finalmente decide si acudirá o no a la Corte Constitucional.

En el sistema chileno, en cambio, siempre fueron las partes del juicio ante el tribunal ordinario -y nunca dicho órgano jurisdiccional-, quienes gozaban de legitimidad activa para formular directamente el conflicto de constitucionalidad ante la Corte Suprema erigida como órgano de con-

25 Ver, en este sentido, el ilustrativo trabajo de Romboli, Roberto (1999). "El control de constitucionalidad de las leyes en Italia", en Teoría y Realidad Constitucional, UNED, No 4, pp. 179-205. 
trol, sin que el juez del tribunal a quo tuviera ningún rol en el planteamiento ni en el desarrollo de la cuestión.

De la noche a la mañana, y sin que los jueces ordinarios hubieran tenido participación alguna en el control de normas, la reforma constitucional del año 2005 los hizo pasar de aparentes legitimados pasivos a reales titulares de legitimación activa para el planteamiento de la cuestión, pero sin dejar claro en función de qué motivos o de qué intereses jurídicos involucrados plantearían el conflicto de constitucionalidad, cuestión que no tiene respuesta ni en la Constitución ni en la Ley Orgánica Constitucional.

Así, en tanto el "legitimado activo" es la parte demandante de inaplicabilidad y en tanto "legitimado activo" es en primer término el titular de la "legitimidad ad causam ordinaria", por ser, al mismo tiempo, quien invoca la titularidad de los derechos constitucionales infringidos; de ahí que se estima que, como condición primaria, debe reconocerse que la legitimación activa de las partes del juicio en el que incide la petición de inaplicabilidad tiene por contenido la titularidad del derecho fundamental que se invoca como vulnerado y al mismo tiempo como norma constitucional infringida en el requerimiento de inaplicabilidad.

Si dicho rol le corresponde a las partes y el juez no puede incursionar en él, subiste la interrogante de la razón para legitimarlo activamente, en tanto es un tercero ajeno al interés de las partes.

\section{3) ¿CUÁl ES ENTONCES EL ROL DEL JUEZ COMO PARTE REQUIRENTE DEL PROCESO DE INAPLICABILIDAD?}

En este sentido, cabe preguntarse si el juez y la parte son equiparables en tanto legitimados activos y demandantes de inaplicabilidad, más allá de la pretendida equiparación fáctica que hacen la Constitución y la Ley No 17.997. Para abordar esta cuestión, se debe constatar una serie de hechos:

(a) La parte de un juicio requiere de inaplicabilidad invocando un resultado inconstitucional consistente en afectación de derechos fundamentales, de los cuales señala ser titular, el cual se produce amparado en un acto de aplicación de la norma legal.

(b) La norma constitucional, al concebir la inaplicabilidad como control de aplicación, hace destinatario de los efectos de la sentencia al juez llamado a aplicar la norma, alterando el resultado del proceso en que esta incide y desplazando la legitimación pasiva desde el legislador hacia el juez, en tanto es el autor del acto de aplicación cuestionado por sus efectos constitucionalmente ilícitos.

(c) El acto de requerir por una parte de un juicio persigue disponer de sus derechos fundamentales, de carácter subjetivo, que se verán, 
eventualmente, amagados por una sentencia u otra resolución judicial fundada en una norma específica, situación a la cual el requirente se opone.

(d) El juez, a pesar de ser el destinatario de la sentencia de inaplicabilidad, puede, paradojalmente, ser también un sujeto requirente según la Carta Fundamental.

Asumiendo que el rol procesal de las partes del juicio, titulares de los intereses litigiosos, es totalmente diferente del que corresponde al juez de la causa, tercero imparcial y ajeno que adjudica, ¿cuál es el contenido de la legitimidad "ad causam" del juez que requiere de inaplicabilidad?

La respuesta no es sencilla, pero parece obvio, en primer término, que el juez de la causa no fundará el requerimiento de inaplicabilidad en la afectación de derechos propios, pues el no es "parte" del conflicto, sino un tercero externo al mismo, que además debe resolverlo conforme a Derecho y en nombre del poder estatal.

Así, la legitimación ad causam del juez requirente no debiera estar en la afectación de derechos fundamentales de las partes, pues pareciera que en esta materia es necesario recordar el carácter subjetivo de los mismos y lo que eso significa en cuanto a su titularidad estrictamente individual y su carácter disponible. Asimismo, el juez debe igualdad de trato a las partes, como contrapartida de la exigencia de imparcialidad del tribunal, por lo cual, a menos que se acepte un activismo judicial y paternalista respecto de los intereses de una de las partes, por el cual se crea que el juez sabe mejor que la persona titular del derecho lo que quiere hacer con él o lo que le resulta más conveniente, pareciera que el fundamento de la legitimidad ad causam del juez no se encuentra en los derechos fundamentales de las partes, pues en el sistema chileno ellas pueden invocarlos directamente ante el Tribunal Constitucional para plantear la cuestión de inaplicabilidad, prescindiendo así de la labor de prejudicialidad que sistemas como el español o el italiano asignan al juez ordinario en el planteamiento de la cuestión ${ }^{26}$, en tanto legitimado activo exclusivo para comparecer e invocar la norma constitucional ante el Tribunal Constitucional en sede de control de normas, ante el cual -en dichos sistemas- la parte está impedida de comparecer.

En pocas palabras, el rol y los intereses del juez común y de las partes en un proceso de control de constitucionalidad de normas es, conceptual y materialmente, diferente, sin que la normativa constitucional ni la ley orgánica del Tribunal se hagan cargo del asunto para poder determinar el contenido y los límites de dicha diferenciación.

26 Ver, en este sentido, Pizzorusso (2007) 118 y ss. 
Al mismo tiempo, pretender fundar el requerimiento del juez en un deber de proteccionismo sobre una parte frente a la otra, vendría a justificar una manifestación de paternalismo activista, permitiendo que un órgano del Estado, un tribunal, entre a disponer de derechos fundamentales ajenos, eventualmente contra la voluntad de su propio titular, en un coto vedado al poder estatal.

Cabe hacer presente que lo razonado precedentemente puede encontrar su excepción, por ejemplo, en el caso de la judicatura penal, área en la que el legislador, obedeciendo al pensamiento garantista como inspiración, asume la evidente desigualdad de las partes: el imputado versus el ius puniendi estatal dotado de todas sus herramientas, frente a lo cual se han establecido una serie de resguardos legales, entre los cuales aparecen las funciones del Juez de Garantía en tanto jurisdictor de cautela, disponiendo el artículo 10 del Código Procesal Penal que "En cualquiera etapa del procedimiento en que el juez de garantía estimare que el imputado no está en condiciones de ejercer los derechos que le otorgan las garantías judiciales consagradas en la Constitución Política, en las leyes o en los tratados internacionales ratificados por Chile y que se encuentren vigentes, adoptará, de oficio o a petición de parte, las medidas necesarias para permitir dicho ejercicio", en una verdadera norma de conexión del ejercicio de derechos fundamentales con la labor de "jurisdicción de cautela", que, en primer término, permitiría plantear inaplicabilidades al juez, en función de los derechos del imputado que pudieren verse afectados en el proceso penal, pero con la misma bandera que a los otros jueces se lo impide: el resguardo de la igualdad de las partes frente al órgano jurisdictor.

Por otro lado, en materia de acciones constitucionales, cuando se ha permitido la comparecencia de cualquier persona a nombre del titular de los derechos fundamentales amagados, se ha establecido de manera expresa lo que llamaremos una "norma de conexión" entre el titular del derecho invocado y la persona que acciona en el tribunal, como ocurre con los preceptos de los artículos 20 y 21 de la Carta Fundamental en materia de protección y amparo.

Pero, ¿qué ocurre a falta de normas de conexión como la antes enunciada respecto del juez de garantía? En primer lugar hay que constatar que no existen preceptos conectivos generales de esta tipología en materia de inaplicabilidad por inconstitucionalidad, ni en la Ley Orgánica ni en la propia Constitución.

Si se asume la legitimación activa del juez como norma de conexión en sí misma, aparecerá la problemática del adelantamiento de opinión y el quiebre de la igualdad de las partes, por lo que habrá que asumir que no puede el tribunal ocurrir de inaplicabilidad actuando en representación, -o activismo- de los derechos de las partes. En efecto, en función de los artículos 79, 80 y 84 de la Ley Orgánica del Tribunal Constitucional, el juez debe plantear -entre otros requisitos- las normas infringidas, cómo 
se produce la infracción, y de qué manera resulta decisiva la aplicación de las mismas, lo que forzosamente significará interpretar, anticipar juicio y señalar como se puede resolver antes de dictar la resolución que aplica el precepto, cuestión que se ve acentuada en favor de una parte si se invocan sus derechos fundamentales. Así, exigir al juez y a las partes el mismo grado de concreción argumentativa en el requerimiento conduce a consecuencias no deseables, y resulta difícil suponer que el constituyente derivado de 2005 quisiera que el juez de la causa realizara activismo, paternalismo y adelantamiento de juicio, más si ello se estableció en la misma norma, la Constitución, que garantiza el acceso al racional y justo procedimiento.

De esta forma, pareciera ser el fundamento constitucional de la legitimación del juez de la causa forzosamente diferente del contenido ad causam de la capacidad para comparecer que se reconoce a las partes del juicio, a menos que se conciba el control de inaplicabilidad como carente de contenido concreto por parte del juez en tanto legitimado activo, lo que lleva a concebir su requerimiento como puramente abstracto. Si se asume que nos encontramos frente a un modelo concreto, pareciera que se debe recurrir a una suerte de legitimación extraordinaria de tipo imperfecta o incompleta, que habilitaría al juez a formular un requerimiento de inaplicabilidad -desde esta perspectiva, al menos- incausado, al no necesitar interés en él.

De esta forma, asumiendo que el juez no ve afectados intereses ni derechos propios y que su trato hacia los intereses de las partes debe ser igualitario, pareciera que en lugar de buscar una "legitimación ad causam", se debiera recurrir a una conceptualización que reconozca un fundamento de legitimación extraordinaria para el juez que conoce del asunto, consagrada expresamente por el inciso undécimo del artículo 93 de la propia Carta Fundamental.

La legitimación del juez puede ser calificada de extraordinaria en la medida que no se la subordina a intereses propios y sería indebido ligarla al perjuicio constitucional de la parte, cuestión que -como se viera- puede tener graves consecuencias si se entiende de manera irrestricta.

La diferenciación del contenido y del fundamento del requerimiento del juez que conoce de la causa era un interrogante que antes de la dictación de la Ley $\mathrm{N}^{\circ} 20.381$ admitía un campo amplio de reflexión, y, por cierto, un mayor margen de maniobra para las salas del Tribunal Constitucional a la hora de determinar la admisibilidad de requerimientos de jueces, usualmente más breves y sucintos que los de partes. Hoy dicho margen de apreciación en el papel no existe, por lo que esta no es una cuestión simple.

La citada Ley No 20.381 reguló el actual procedimiento de inaplicabilidad, dentro del cual están los requisitos materiales o de contenido del requerimiento ya señalados, de admisión a trámite y de admisibilidad, 
en una normativa que impide responder la pregunta de cuáles son las diferencias entre el juez y las partes, el rol del juez en el planteamiento de la cuestión de inaplicabilidad, pues tanto al juez como a las partes de la gestión el artículo 79 de la Ley Orgánica del Tribunal Constitucional les exigió los mismos requisitos de admisión a trámite para poder dar curso a su requerimiento, a saber:

(a) Contener una exposición clara de los hechos y fundamentos en que se apoya;

(b) Explicitar cómo ellos producen como resultado la infracción constitucional que se invoque; $y$

(c) Expresar el o los vicios de inconstitucionalidad que se aducen, con indicación precisa de las normas constitucionales que se estiman transgredidas.

Asumido lo anterior, es un hecho que el juez debe expresar fundamentos específicos y desarrollados, de hecho y de Derecho y explicitar cómo se producirá el resultado contrario a la Constitución, lo que no deja de ser paradójico en la medida que se representan futuras resoluciones que él mismo dictará, las adelanta de manera hipotética y las tacha de inconstitucionales, para poder cuestionar su normativa habilitante.

\section{4) LA DIFERENCIACIÓN DE LA NATURALEZA DEL REQUERIMIENTO DEL JUEZ DE LA CAUSA EN RELACIÓN AL FORMULADO POR LA PARTE EN LA JURISPRUDENCIA ${ }^{27}$}

Reconociendo las diferencias entre el requerimiento de parte y del tribunal, se ha razonado, incluso antes de la dictación de la Ley $\mathrm{N}^{\circ}$ 20.381, que "si es el juez el que se encuentra enfrentado a una duda de constitucionalidad acerca de un precepto legal que pueda aplicar como norma decisoria litis en el proceso que sustancia, es él quien debe directamente requerir ante este Tribunal Constitucional manifestando en forma expresa su voluntad de obtener una sentencia que se pronuncie sobre la materia, constituyéndose, de esta forma, en sujeto activo de la acción de inaplicabilidad. Asimismo, tal decisión debe traducirse en un requerimiento formal de inaplicabilidad por inconstitucionalidad que cumpla con los requisitos exigidos por las normas constitucionales y legales"28,

27 Revisada la abundante jurisprudencia del Tribunal Constitucional, solo fueron encontradas tres sentencias, definitivas o de inadmisibilidad, que se refirieran a este tema, las cuales son citadas en el presente trabajo.

28 Tribunal Constitucional de Chile, sentencia de 12 de febrero de 2009, Rol No 1324 Requerimiento de la Corte de Apelaciones de Iquique para que el Tribunal Constitucional se pronuncie respecto de la solicitud de Maritza Molina Flores y otros, contenida en el 
por lo que "resulta necesario señalar que si lo promueve el juez que conoce de la respectiva gestión pendiente, el requerimiento de inaplicabilidad por inconstitucionalidad de un precepto de jerarquía legal debe satisfacer los requisitos de sustentación, claridad y precisión mencionados en la normativa constitucional y legal ya aludida" (Rol 1324-09, considerando $\left.7^{\circ}\right)$.

A la luz de los pasajes jurisprudenciales transcritos, daré por sentado que el juez debe aludir un resultado de aplicación y tacharlo de inconstitucional para requerir, y también que, salvo en materia penal, no resulta idóneo hacerlo invocando la titularidad de derechos subjetivos que en realidad corresponden a las partes.

Superado el paradigma del juez de "El espíritu de las leyes" planteado por el barón de Montesquieu, la pregunta que surge de la relación entre Constitución y juez ordinario sería: ¿cuál es el rol que tiene la judicatura ordinaria respecto de la Constitución y su supremacía?

\section{5) LA DOBLE SUMISIÓN DEL JUEZ A LA LEY Y A LA CONSTITUCIÓN COMO FUNDAMENTO DE LA LEGITIMACIÓN ACTIVA DEL ÓRGANO JURISDICCIONAL}

Cabe señalar que el paso del viejo Estado Legal al Estado Constitucional hace que el principio de omnipotencia del legislador se vea debilitado, de manera tal que el juez deja de ser un mero esclavo de la ley y deja de tener la sumisión total y exclusiva a ella como horizonte único de obediencia, al punto que "la vinculación del juez a la ley se debilita, porque una norma más alta le autoriza a cuestionar su validez o incluso a negarla y a extraer consecuencias necesarias de esta negación, inaplicando la ley que estima inválida o, en el sistema europeo, expulsándola del ordenamiento" 29 , en el paso del juez esclavo de la ley al juez obligado por ella, pero -al mismo tiempo- promotor de la supremacía constitucional.

Hoy, el rol del juez visto desde la Constitución ha cambiado y cabe preguntarse entonces ¿qué interés puede tener el juez, encargado de aplicar la ley, en el proceso de inaplicabilidad por inconstitucionalidad de la misma? Cuestión que debe abordarse en el marco de la articulación sistémica entre la judicatura ordinaria y la judicatura constitucional, propio de todo sistema de control estructurado en la matriz concentrada europea.

recurso de protección Rol 66-2009, que conoce esa Corte, para que se declare la inaplicabilidad de diversos preceptos del Estatuto Administrativo, Ley No 18.834, considerando $2^{\circ}$. Disponible en http://www.tribunalconstitucional.cl/index.php/sentencias/view/1104, [Fecha de visita 15 de octubre de 2010].

29 Rubio Llorente, Francisco (1997). "La interpretación constitucional”, en él mismo: La Forma del Poder, estudios sobre la Constitución", Madrid: Centro de Estudios Constitucionales, p. 282. 
En este sentido, en el sistema constitucional español, de iniciativa exclusivamente judicial, es posible sostener que existe un "monopolio (auxiliado) del control de constitucionalidad de las normas con fuerza de ley" 30 , que se traduce en que "la actuación de la jurisdicción constitucional implica la resolución por esta de un problema constitucional suscitado, precisamente, por los órganos judiciales a través de la cuestión de inconstitucionalidad" 31 , de manera tal que puede perfectamente plantearse que en este aspecto el juez común cumple la misma función colaborativa de la labor depurativa del Tribunal Constitucional, en lo que el mismo autor ha denominado como "monopolio (auxiliado) del control de constitucionalidad de las normas con fuerza de ley", por el cual "la actuación de la jurisdicción constitucional implica la resolución por esta de un problema constitucional suscitado, precisamente, por los órganos judiciales a través de la cuestión de inconstitucionalidad"32.

Estamos en presencia, entonces, de un monopolio auxiliado porque el modelo concentrado exige que sea solo el Tribunal Constitucional el que tenga competencia en el asunto, pero en un contexto normativo en el cual el juez ordinario también está sometido a la norma fundamental, motivo por el cual colabora al ejercicio de la potestad de depuración de normas planteando requerimientos, recordando que es el juez quien formula la cuestión en España. En el caso chileno, este monopolio propio del sistema concentrado es extrapolable por la vía del artículo 7 de la Constitución, en relación a los numerales 6 y 7 del artículo 93 de la misma, pues si bien el proceso de inconstitucionalidad abstracta y erga omnes puede ser iniciado de oficio o por acción pública, tiene como presupuesto una sentencia estimatoria de inaplicabilidad, que presupone un requerimiento, por lo cual el monopolio de control de normas en Chile se encuentra auxiliado no solo por los jueces ordinarios, sino también por las partes de los procesos seguidos ante cualquier tribunal.

$\mathrm{Al}$ mismo tiempo, el tribunal ordinario en Chile, en tanto órgano del Estado, se encuentra obligado por el art. 6 de la Constitución, que le exige "someter su acción a la Constitución y a las normas dictadas conforme a ella" y, por otra parte, debe además "garantizar el orden institucional de la República”, por lo que el fundamento de la legitimación extraordinaria del juez puede perfectamente estar en dicha norma, de interés público y de orden abstracto.

Por otra parte, debe tenerse presente que a partir del texto del artículo 6 de la Carta Fundamental se puede conceptualizar en nuestro sistema lo que Manuel Aragón ha denominado "la doble sumisión” por parte

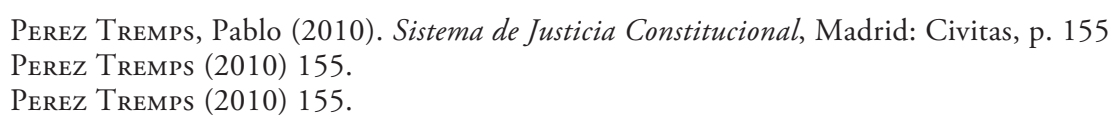


de los jueces ordinarios, consistente en que el juez está sometido "a la Constitución, que han de cumplir y, por lo mismo, no pueden ignorar o inaplicar, y a la ley, a la que están sometidos y de la que no pueden disponer, lo que significa que no pueden inaplicarla por razón de invalidez. La solución de esta aparente contradicción estará en la cuestión de inconstitucionalidad, que permite a los jueces, no pudiendo disponer de la ley, no estén obligados tampoco a aplicarla cuando la consideren inconstitucional. Por medio de esta cuestión se hace posible la supremacía jurídica de la Constitución en todos los ámbitos del ordenamiento sin que se rompa el principio de la sumisión de los jueces a la ley"33.

A partir del deber de doble sumisión, el Tribunal Constitucional español, en una época tan temprana como 1981, sostuvo que la sumisión a la Constitución, superior a la sumisión al legislador, no podía ser una excusa para eludir esta última y dar pie al control difuso; en efecto, sostuvo que el constituyente "ha preferido, para evitarlo, sustraer al juez ordinario la posibilidad de inaplicar la ley que emana del legislador constituido, aunque no la de cuestionar su constitucionalidad", según razonó en la sentencia $17 / 81^{34}$, de 1 de junio de 1981 . Tras la reforma constitucional del año 2005, lo que planteó hace casi 30 años el joven tribunal español parece plenamente extrapolable al caso chileno, al introducirse el planteamiento de la cuestión de inaplicabilidad a iniciativa judicial.

Es por ello que en el sistema constitucional espańol, es posible sostener que el planteamiento de la cuestión de constitucionalidad "es un auténtico deber para el juez, fundado en un interés público" ${ }^{35}$, que no es otro que la supremacía constitucional.

Haciendo aplicación de dichos principios, si el constituyente derivado del ańo 2005 confirió al Tribunal Constitucional la facultad de controlar la constitucionalidad de la ley de forma expresa, y no lo hizo con otros órganos, hemos de entender que el juez común no está habilitado, para ello, lo que es acorde con el principio de competencia del artículo 7 o de la Constitución, que establece que los órganos del Estado, judicatura inclusive, no tiene más facultades que las expresamente conferidas por la Constitución y las leyes, y en este caso la reforma lo que ha hecho

33 Aragón Reyes, Manuel (2004). "El juez ordinario entre legalidad y constitucionalidad" en Carbonell, M. / Fix Fierro, H. / Vázquez, R. (coordinadores): Jueces y Derecho. Problemas contemporáneos, México D.F.: Editorial UNAM-Porrúa, p. 183.

34 Tribunal Constitucional de España, sentencia de 1 de junio de 1981, Rol No 17/1981, cuestión de inconstitucionalidad promovida por el Magistrado Juez de Primera Instancia núm. 7 de Barcelona, sobre el art. 252.2 y 3 de la Compilación del Derecho Civil Especial de Cataluña, de 21 de julio de 1960, en relación con el art. 39.2 de la Constitución”. Disponible en http://www.boe.es/aeboe/consultas/bases_datos/doc.php?coleccion=tc\&id=SEN TENCIA-1981-0017 [Fecha de visita 23 de septiembre de 2010].

35 Pérez Tremps, Pablo (1985). Tribunal Constitucional y Poder Judicial, Madrid: CEC, p.127. 
es transformar derechamente al juez ordinario en sujeto legitimado para plantear la cuestión por la vía de reconocer el planteamiento de la cuestión como una atribución.

En virtud de ello, pareciera que el Tribunal Constitucional es el único órgano con potestades para declarar contraria a la Constitución una norma legislativa, lo que, ni aun a pretexto de circunstancias extraordinarias el juez ordinario puede obviar. Lo anterior, a mi juicio, dejaría cerrada la discusión planteada hace ya tiempo por el profesor Lautaro Ríos ${ }^{36}$ en orden a que el antiguo texto del artículo $6^{\circ}$ dejaba abierta la puerta al control difuso, por la simple vía de que al estar el juez obligado a respetar la Constitución y las leyes dictadas conforme a ella, no podía aplicar una ley que considerare contraria a la Carta fundamental.

Hoy, desde la perspectiva de la doble sumisión y al plantearse expresamente que el juez es titular de la acción de inaplicabilidad, en lugar de haberse dictado una norma que lo facultara de manera expresa para inaplicar de forma directa, en la práctica se le reconoció la competencia privativa para declarar la inaplicabilidad por inconstitucionalidad al Tribunal Constitucional de forma expresa, y por tanto excluyente, en la medida que tanto el juez ordinario como el Tribunal Constitucional, de conformidad al artículo 7 , no tienen más atribuciones que las expresamente reconocidas por el Derecho.

Así, la Constitución, respecto del juez ordinario, no le confirió potestades de inaplicar y sí le confirió la potestad de plantear la cuestión ante el Tribunal constitucional, actuando como requirente, titular o legitimado activo de una acción, que ejercerá como actor en un nuevo proceso de inaplicabilidad, ante un tribunal distinto, que actúa investido de jurisdicción para resolver dicho conflicto constitucional.

Atendido lo anterior, el sostener que un tribunal ordinario o especial puede inaplicar la ley sin plantear la cuestión de inaplicabilidad ante el Tribunal Constitucional implicaría una vulneración a los artículos 7 y 93 de la Constitución y una autoatribución de potestades inexistentes por parte del tribunal ordinario.

Por otra parte, se estaría en presencia de un acto de verdadera autotutela constitucional, pues el juez es parte del conflicto constitucional, estaría haciendo justicia por su propia mano en dicho litigio, resolviéndolo por sus propios medios e imponiendo su decisión al amparo de su poder, sin el proceso de inaplicabilidad previo y legalmente tramitado ante el tribunal predeterminado por la ley, de la forma que exige el numeral $3^{\circ}$ del artículo 19 de la Carta fundamental.

36 Ver, en este sentido, Ríos Álvarez, Lautaro (2002). "El control difuso de la constitucionalidad de la ley en Chile y otros países de América". Anuario Iberoamericano de Justicia Constitucional, No 6, Centro de Estudios Políticos y Constitucionales, p. 417 y ss. 
No debe olvidarse, como ya se ha dicho, que el tribunal ordinario es parte del conflicto, sea como requirente o como destinatario de la sentencia de inaplicabilidad, en tanto es el aplicador de la norma que se cuestiona. De ahí que se estime que ya no se puede leer posibilidad alguna de control difuso, mas aun si los tribunales ordinarios, en tanto órganos del Estado y al tenor del nuevo artículo 6, son garantes del orden institucional, lo que implica respeto irrestricto a los poderes de los otros órganos del Estado, enmarcado en el citado principio de competencia, lo cual forzosamente lleva a abordar el tema desde la perspectiva de la doble sumisión planteada por Aragón, cuyo enfoque permite superar la vieja discusión acerca de la procedencia del control difuso en el sistema chileno, que se deducía $-y$ todavía se plantea ${ }^{37}$ - a partir del tenor literal del mismo artículo $6^{\circ}$.

En este contexto, es menester tener presente que la tesis de la doble sumisión implica que el juez tiene dos mandantes, traducidos en dos referentes de obediencia: la Constitución y la ley, lo cual no generará problemas en la medida que ambos sean acordes y, al contrario, sí generará disfuncionalidades sistémicas cuando no sean acordes, pues lo legal será en ese caso inconstitucional y lo constitucional será en ese caso ilegal, generándose un conflicto de fuentes, que será formulado por el juez y resuelto de manera monopólica por el Tribunal Constitucional.

Así, pareciera que el acto judicial de requerir de inaplicabilidad obedece más bien al cumplimiento de un deber funcional del órgano jurisdiccional y no a un acto de voluntad o de cautela de derechos fundamentales de las partes, que actúan por sí solas en ese orden. Plantearé entonces que el juez en realidad actúa cautelando la supremacía de la Constitución como deber que cumplir y además como interés abstracto o de orden público, invoca la Constitución como Derecho objetivo y material al cual está sometido conjuntamente con una ley que juzga incompatible con ella, lo que indirectamente incidirá en el interés de las partes en un proceso. Así, la incidencia de la inaplicabilidad en la dimensión subjetiva de los derechos de las partes es solo indirecta - a diferencia del requerimiento de parte, fundado directamente en ellos-, pues en la medida que observe una contrariedad con la Constitución, que se producirá en el proceso que tramita, la declaración de inaplicabilidad incidirá en dichos derechos de las partes y no del juez.

37 En orden a que el juez de la instancia sí podría declarar inaplicable un precepto legal cuando tiene convicción suficiente acerca de su inconstitucionalidad, ver el trabajo de MARTínez Estay, José Ignacio (2005). "Recurso de Inaplicabilidad, Tribunal Constitucional y juez ordinario. en la reforma constitucional”, en Nogueira Alcalá, Humberto (coord.): La Constitución reformada de 2005, Santiago: Editorial Librotecnia, pp. 29-52. 


\section{6) EL REQUERIMIENTO DEL JUEZ Y EL REQUERIMIENTO DE LAS PAR- TES NO PUEDEN TENER EL MISMO CONTENIDO}

Sin referirse a la doble sumisión y sin tratar de conceptualizarla en el sistema constitucional chileno, a partir de la diferencia que subyace entre el requerimiento de parte y el requerimiento del juez, se ha razonado por el Tribunal Constitucional que: "La Carta Fundamental, en su artículo 93, inciso decimoprimero, indica que "la cuestión podrá ser planteada por cualquiera de las partes o por el juez que conoce del asunto", lo que da cuenta de la situación diversa en que se encuentran las partes en la gestión respecto del juez que debe aplicar la norma, en su caso" 38 .

"QUINTO: Que la habilitación al juez de la causa para entablar la cuestión de inaplicabilidad por inconstitucionalidad de un precepto legal, inédita en nuestro ordenamiento jurídico, tiene como antecedente en el derecho comparado (en Alemania, Italia y España)la facultad del juez para consultar al Tribunal Constitucional las dudas de constitucionalidad que le merezca una norma jurídica; SEXTO: Que la aludida cuestión de inaplicabilidad se encuentra sometida a requisitos comunes, sea el juez o las partes quienes la formulen, ya que la disposición constitucional no hace distinción alguna. No obstante lo anterior, no puede desatenderse que el interés legítimo que sustenta la acción no es exactamente el mismo en ambos casos. Las partes del juicio procuran la tutela de un derecho subjetivo o de un interés protegido; el juez, por su lado, vela por la supremacía constitucional, dando cumplimiento al mandato del artículo $6^{\circ}$ de la Carta Fundamental, pues su función propia es resolver una controversia entre partes, decidiendo imparcialmente el asunto concreto sometido a su conocimiento, de acuerdo a la Constitución y a las leyes" 39 .

38 Tribunal Constitucional de Chile, sentencia de 18 de diciembre de 2008, Rol No 1065, "Requerimiento de inaplicabilidad del Juez del Juzgado de Garantía de Puerto Montt respecto del artículo 149, inciso segundo, del Código Procesal Penal, en la causa RIT N ${ }^{\circ}$ 3798-2008, RUC No 0800363671-3, seguida en contra de César Uribe Villegas por el delito de robo con violencia", considerando $11^{\circ}$. Disponible en http://www.tribunalconstitucional.cl/index.php/sentencias/view/1070 [Fecha de visita 23 de septiembre de 2010].

39 Tribunal Constitucional de Chile. Sentencia de noviembre de 2008. Rol No 1029-07 "Requerimiento del Juez del Séptimo Juzgado de Garantía de Santiago deduciendo una acción de inaplicabilidad por inconstitucionalidad respecto de diversos artículos del Código de Justicia Militar, en causa Rit 8368-2008 de ese Juzgado de Garantía”, considerandos $5^{\circ}$ y $6^{\circ}$. Disponible en http://www.tribunalconstitucional.cl/index.php/sentencias/view/1050 [Fecha de visita 23 de septiembre de 2010]. 
Por lo expuesto, es posible afirmar que el grado de concreción que se le puede exigir al juez ordinario en cuanto al contenido de su requerimiento no es el mismo, sino claramente es menor ${ }^{40}$ al que debe contener un requerimiento de parte dotada de legitimación ad causam, y en eso pareciera que el legislador orgánico cometió un error conceptual, pues asimiló el requerimiento de parte y el del juez, aun cuando su motivo y su contenido son diferentes.

En este ejercicio el requerimiento del juez debiera ser una herramienta de ultima ratio, pues en su conciencia el juez "especula" al adelantar una supuesta subsunción de hechos en la norma legal que debe aplicar, concluye un eventual resultado, tras lo cual procede a examinarlo y enjuiciarlo, calificándolo como contrario a la Constitución pero ajustado a la ley habilitante, y admitiendo que la norma legal usualmente permite un haz de diferentes interpretaciones, el juez ordinario podría eludir aquellas que producen el resultado contrario a la Constitución, recurriendo a los elementos lógico y sistemático de interpretación de la ley, haciendo innecesaria la declaración de inaplicabilidad como medio preventivo de un resultado contrario a la Constitución, en un ejercicio de interpretación conforme que puede perfectamente fundamentarse en la armonización de la doble sumisión y también en el deber de garantía del orden institucional de la República, contenido en el propio artículo $6^{\circ}$.

En este sentido el juez, mediante el acto de requerir de inaplicabilidad, lo que pareciera estar solicitando es la determinación del Derecho objetivo aplicable o su armonización con la Carta Fundamental, a la vez que plantea una verdadera "cuestión de conciencia jurídica", al estimar que sus dos grandes referentes de obediencia, la Constitución y la ley, lo llevan a horizontes diferentes e incompatibles, tras lo cual considera prioritario el camino constitucionalmente adecuado, que es recurrir al monopolio de depuración de normas del Tribunal Constitucional.

Así, el juez, al estimar que debe requerir, realiza forzosamente un acto de análisis, opinión, enjuiciamiento y voluntad de no aceptación acerca de la situación jurídica de las partes y los efectos futuros del proceso que él mismo ha de conocer y resolver, en un verdadero acto de "rebelión" en contra de lo que el legislador en principio le ordena, lo cual aparece amparado, como ya se ha dicho, por la doble sumisión que establece la Carta Fundamental en su artículo 6 y canalizado por la vía del numeral $6^{\circ}$ y el inciso undécimo de su artículo 93.

La "doble sumisión" del tribunal ordinario enunciada por Manuel Aragón implica asumir que el juez es un protagonista del planteamien-

40 Es menor en la medida que no se refiere ni emana directamente de un derecho fundamental su titularidad, pero sigue siendo concreto en la medida que siguen presentes el juicio de relevancia, la ponderación de los antecedentes del caso y la doble relación entre el mismo y la cuestión planteada. 
to de una cuestión de constitucionalidad, pero de la misma forma, la existencia del modelo concentrado y de las normas antes citadas llevan a reconocer que no es el propio juez ordinario quien dispone y determina los alcances de dicha doble sumisión, quedando obligado a plantear el conflicto ante una jurisdicción especial, que es el Tribunal Constitucional.

Se constata así que el interés de las partes y el interés del juez de la causa para requerir la inaplicabilidad de una norma efectivamente son del todo diferentes en nuestro sistema, lo cual deriva justamente de la concurrencia de legitimación activa para juez y para las partes, de manera simultánea y autónoma, a diferencia de sistemas concentrados como el español y el italiano, en los cuales el incidente previo al auto motivado por el cual se requiere, genera una confluencia y un verdadero consenso entre el juez requirente -único habilitado para elevar el libelo de constitucionalidad- y la parte que le formuló la petición de acudir al Tribunal Constitucional.

\section{CONCLUSIONES}

(a) La legitimación activa de las partes y del juez ordinario en el proceso de inaplicabilidad por inconstitucionalidad son conceptualmente diferentes, cuestión que no está clarificada ni en la Constitución ni en la Ley Orgánica del Tribunal Constitucional, que asimila y confunde ambos requerimientos.

(b) La legitimación de las partes del juicio es causada o "ad causam", reconociendo como contenido a un derecho subjetivo -fundamentalde rango constitucional que se ve involucrado en el proceso.

(c) El requerimiento de la parte persigue evitar un acto jurisdiccional que resulte lesivo de sus derechos fundamentales.

(d) El requerimiento de parte es una solicitud de tutela judicial efectiva.

(e) La legitimación del juez es diferente, de carácter extraordinaria, en función de un principio objetivo y de orden público, cual es la supremacía de la Constitución como regla jurídica autónoma.

(f) El requerimiento del juez tiene por finalidad, además, armonizar su obligación de obediencia a la ley y al mismo tiempo a la Constitución, en el marco de un sistema concentrado de control de normas.

(g) En función de las conclusiones anteriores, el grado de concreción del requerimiento del juez no puede ser el mismo que el exigido para un requerimiento de parte, pues su sustento y su cimiento jurídico en un caso es un derecho concreto y de titularidad subjetiva y en el caso del juez es un interés abstracto y de orden público, que por la vía del Derecho material contenido en la Constitución incidirá indirectamente en los derechos de las partes. 


\section{BIBLIOGRAFÍA}

- Aldunate Lizana, Eduardo (2007). "La reforma constitucional del año 2005 desde la teoría del Derecho y la teoría de la Constitución”. Revista de Derecho Público No 69, tomo I, pp.35-57

- Alsina, Hugo (1950). Derecho procesal civil y comercial, tomo I, Buenos Aires: Ediar.

- Aragón Reyes, Manuel, (2004). "El juez ordinario entre legalidad y constitucionalidad” en Carbonell, M. / Fix Fierro, H. / Vázquez, R. (coordinadores): Jueces y Derecho. Problemas contemporáneos, México D.F.: Editorial UNAM-Porrúa.

- Atria Lemaitre, Fernando (2001). "Inaplicabilidad y coherencia: contra la ideología del legalismo". Revista de Derecho de la Universidad Austral de Chile, Vol.12, No 1.

- Balaguer Callejón, Francisco et alii (2005). Derecho Constitucional, tomo II, Madrid: Ed. Tecnos.

- Canosa Usera, Raúl (1992). La legitimación autonómica en el proceso constitucional, Madrid: Ed. Trivium.

- Cossio, José Ramón (2007). "Las partes en las controversias constitucionales", en Cuestiones Constitucionales, No 16, enero-junio, pp. 89-135.

- Fermandois V., Arturo (2008). "Inaplicabilidad y control concreto del Tribunal Constitucional: enjuiciando la arbitrariedad en la aplicación de la ley". Actualidad Jurídica, $\mathrm{N}^{\circ} 17$.

- Gómez Bernales, Gastón (2005). "La reforma constitucional a la jurisdicción constitucional”, en Zúñiga Urbina, Francisco (coordinador). Reforma constitucional, Santiago: LexisNexis.

- Groppi, Tania (2009). "Titularidad y legitimación ante la jurisdicción constitucional. una perspectiva comparada”, en Ferrer MacGregor, Eduardo / Zaldívar Lelo de Larrea, Arturo (coordinadores): La ciencia del Derecho procesal constitucional. Estudios en homenaje a Héctor Fix-Zamudio en sus cincuenta años como investigador del Derecho, tomo III, México D.F.: UNAM, pp. 227-255.

- Gozaini, Osvaldo (1996). "Legitimación y proceso", en Morello, Augusto (coord.): La Legitimación, Buenos Aires: Abeledo Perrot, pp. 39-63.

- Martínez Estay, José Ignacio (2005). "Recurso de Inaplicabilidad, Tribunal Constitucional y juez ordinario. en la reforma constitucional”, en Nogueira Alcalá, Humberto (coord.): La Constitución reformada de 2005, Santiago: Editorial Librotecnia, pp. 29-52.

- Montero Aroca, Juan (1994). La legitimación en el proceso Civil, Madrid: Editorial Civitas.

- Nogueira Alcala, Humberto (2003). “Tópicos sobre jurisdicción constitucional y tribunales constitucionales", Revista de Derecho de la 
Universidad Austral (Chile), Vol.14, p.43-66. Disponible en http:// mingaonline.uach.cl/scielo.php?script=sci_arttext\&pid=S07180950 2003000100003\&lng=es\&nrm=iso [Fecha de visita: 3 noviembre de 2010].

- Núñez Poblete, Manuel Antonio (2008). "El control de la igualdad en la aplicación de la ley como factor de expansión del control concreto de constitucionalidad de las leyes", en Aa. Vv.: Sentencias destacadas 2007, Santiago: Instituto Libertad y Desarrollo, pp. 123-161.

- Pérez Tremps, Pablo (1985). Tribunal Constitucional y Poder Judicial, Madrid: CEC.

- (2010). Sistema de Justicia Constitucional, Madrid: Civitas.

- Pizzorusso, Alessandro (2007). Justicia, Constitución y Pluralismo, Lima: Palestra.

- (2006). "La justicia constitucional italiana, entre modelo difuso y modelo concreto", en Requejo Pagés, Juan Luis (coordinador): Fundamentos, cuadernos monográficos de Teoría del Estado, Derecho Público e Historia constitucional, $\mathrm{N}^{\circ} 4$ de la serie: La rebelión de las Leyes: Demos y nomos: la agonía de la justicia constitucional, Oviedo: Junta General del Principado de Asturias, pp. 239-261.

- Ríos Álvarez, Lautaro (2002) "El control difuso de la constitucionalidad de la ley en Chile y otros países de América”. Anuario Iberoamericano de Justicia Constitucional, No 6, Centro de Estudios Políticos y Constitucionales, pp. 417-444.

(2005). "Trascendencia de la reforma constitucional en la fisonomía y las atribuciones del Tribunal Constitucional”. Estudios Constitucionales, Año 3, Nº 1 (Trascendencia de la reforma constitucional en la fisonomía y las atribuciones del Tribunal Constitucional), pp. 73-95.

- Román Cordero, Cristián (2010). "El requerimiento de inaplicabilidad por inconstitucionalidad como mecanismo de control de la arbitrariedad del legislador". Revista de Derecho Público No 72, pp. 342-182.

- Romboli, Roberto (1999). "El control de constitucionalidad de las leyes en Italia", en Teoría y Realidad Constitucional" UNED, No 4, pp. $179-205$.

- Rubio Llorente, Francisco (1997). "La interpretación constitucional”, en él mismo: La Forma del Poder, estudios sobre la Constitución, Madrid: Centro de Estudios Constitucionales.

- Salas Canceller, Antonio (2006). "La legitimación", en él mismo (coordinador): Las partes: problemática procesal, Madrid: Consejo General del Poder Judicial, pp. 61-85.

- Silguero, Joaquín (1995). La Tutela Jurisdiccional de los Intereses Colectivos a Través de la Legitimación de los Grupos, Madrid: Editorial Dykinson. 
- Torres Muro, Ignacio (2008). "Problemas de legitimación en los procesos constitucionales", Revista de Derecho Político, UNED, No 71-72, pp. 609-640.

- Zúñiga Urbina, Francisco / Vega Méndez, Francisco (2006). "El nuevo recurso de inaplicabilidad por inconstitucionalidad ante el Tribunal Constitucional. Teoría y práctica”. Estudios Constitucionales, Año 4, $\mathrm{N}^{\circ}$ 2, pp. 135-174. 